\title{
Injection Techniques for Common Chronic Pain Conditions of the Hand: A Comprehensive Review
}

\author{
Ivan Urits (D) - Daniel Smoots - Lekha Anantuni - Prudhvi Bandi • \\ Katie Bring - Amnon A. Berger - Hisham Kassem • Anh L. Ngo • \\ Alaa Abd-Elsayed - Laxmaiah Manchikanti · Richard Urman • \\ Alan D. Kaye · Omar Viswanath
}

Received: January 14, 2020 / Published online: February 25, 2020

(C) The Author(s) 2020, corrected publication 2021

\section{ABSTRACT}

Introduction: This compilation presents a comprehensive review of the literature on common chronic pain conditions of the hand. It briefly presents these common conditions with their biological background, diagnosis,

Enhanced Digital Features To view enhanced digital features for this article go to https://doi.org/10.6084/ m9.figshare.11836242.

I. Urits $(\bowtie) \cdot$ A. A. Berger

Department of Anesthesiology, Critical Care, and Pain Medicine, Beth Israel Deaconess Medical Center, Harvard Medical School, Boston, MA, USA e-mail: iurits@bidmc.harvard.edu

D. Smoots · L. Anantuni · P. Bandi · K. Bring · O. Viswanath

Department of Anesthesiology, Creighton University School of Medicine, Omaha, NE, USA

\section{H. Kassem}

Department of Anesthesiology, Mount Sinai

Medical Center, Miami Beach, FL, USA

\section{A. L. Ngo}

Department of Pain Medicine, Pain Specialty Group,

Newington, NH, USA

\section{A. L. Ngo}

Harvard Medical School, Boston, MA, USA

\section{A. Abd-Elsayed}

Department of Anesthesiology, University of

Wisconsin School of Medicine and Public Health,

Madison, WI, USA and common management options. It then presents and compares the latest literature available for injection techniques to treat these diagnoses and compares the available evidence. Methods: A comprehensive literature review was performed in MEDLINE, PubMed, and Cochrane databases from 1996 to 2019 using the terms "hand pain", "injection techniques", "steroid injection", "chronic pain", "osteoarthritis", "rheumatoid arthritis", "carpal tunnel syndrome", "De Quervain's tenosynovitis",

\section{Manchikanti \\ Pain Management Centers of America, Paducah, KY, USA \\ R. Urman \\ Department of Anesthesiology, Perioperative and Pain Medicine, Brigham and Women's Hospital, Boston, MA, USA}

\section{A. D. Kaye}

Department of Anesthesiology, Louisiana State University Health Shreveport, Shreveport, LA, USA

O. Viswanath

Valley Anesthesiology and Pain ConsultantsEnvision Physician Services, Phoenix, AZ, USA

O. Viswanath

Department of Anesthesiology, University of Arizona College of Medicine-Phoenix, Phoenix, AZ, USA 
"ganglion cyst", "gout", "Raynaud's", and "stenosing tenosynovitis".

Results: Hand pain is a common condition with $9.7 \%$ prevalence in men and $21.6 \%$ in women and can cause significant morbidity and disability. It also carries a significant cost to the individuals and the healthcare system, totaling in $\$ 4$ billion dollars in 2003. Injection therapy is an alternative when conservative treatment fails. Osteoarthritis is the most common chronic hand pain syndrome and affects about $16 \%$ of the population. Its mechanism is largely mechanic, and as such, there is controversy if steroid injections are of benefit. Hyaluronic acid (HA) appears to provide substantial relief of pain and may increase functionality. More studies of $\mathrm{HA}$ are required to make a definite judgment on its efficacy. Similarly, steroid ganglion cyst injection may confer little benefit. Carpal tunnel syndrome is a compressive neuropathy, and only temporarily relieved with injection therapy. US-guidance provides significant improvement and, while severe cases may still require surgery, can provide a valuable bridge therapy to surgery when conservative treatment fails. Similar bridging treatments and increased efficacy under US-guidance are effective for stenosing tenosynovitis ("trigger finger"), though, interestingly, inflammatory background is associated with decreased effect in this case. When the etiology of the pain is inflammatory, such as in RA, corticosteroid (CS) injections provide significant pain relief and increased functionality. They do not, however, change the course of disease (unlike DMARDs). Another such example is De-Quervain tenosynovitis that sees good benefit from CS injections, and an increased efficacy with US-guidance, and similarly are CS injections for gout. For Raynaud's phenomenon, Botox injections have encouraging results, but more studies are needed to determine safety and efficacy, as well as the possible difference in effect between primary and secondary Raynaud's.

Conclusions: Chronic hand pain is a prevalent and serious condition and can cause significant morbidity and disability and interferes with independence and activities of daily living. Conservative treatment remains the first line of treatment; however, when first-line treatments fail, steroid injections can usually provide benefit. In some cases, HA or Botox may also be beneficial. US-guidance is increasing in hand injection and almost ubiquitously provides safer, more effective injections. Hand surgery remains the alternative for refractory pain.

Keywords: Carpal tunnel syndrome; Chronic pain; De Quervain's tenosynovitis; Ganglion cyst; Gout; Hand pain; Injection techniques; Osteoarthritis; Raynaud's; Rheumatoid arthritis; Stenosing tenosynovitis; Steroid injection

\section{Key Summary Points}

This compilation presents a comprehensive review of the literature on common chronic pain conditions of the hand. It briefly presents these common conditions with their biological background, diagnosis, and common management options. It then presents and compares the latest literature available for injection techniques to treat these diagnoses and compares the available evidence.

Hand pain is a common condition with $9.7 \%$ prevalence in men and $21.6 \%$ in women and can cause significant morbidity and disability. It also carries a significant cost to the individuals and the healthcare system, totaling $\$ 4$ billion dollars in 2003. Injection therapy is an alternative when conservative treatment fails.

In some cases, HA or Botox may also be beneficial. US-guidance is increasing in hand injection and almost ubiquitously provides safer, more effective injections. Hand surgery remains the alternative for refractory pain.

\section{INTRODUCTION}

Hand pain can present in a variety of musculoskeletal conditions, with diverse symptoms and long-term implications. The prevalence of hand pain is $9.7 \%$ in men and $21.6 \%$ in women, 
while the prevalence of hand disability is $7.2 \%$ in men and $17.8 \%$ in women [1]. These hand conditions are most common in adults over 50 years of age and can ultimately decrease overall quality of life. Individuals with problems of functionality often have worse prognoses, while those with pain only have a greater chance of improvement with time [2]. Chronic hand pain and disability create significant burden on the healthcare system. Gout alone was estimated to cost $\$ 4$ billion in 2003, which translates to $\$ 666$ per patient [3]. Statistics for other hand pain conditions have not been explored or are not as accessible but likely have similar healthcare burden.

In this review, we will discuss injection techniques for common chronic pain conditions of the hand. These conditions include osteoarthritis (OA), rheumatoid arthritis (RA), carpal tunnel syndrome (CTS), De Quervain's tenosynovitis, ganglion cyst, gout, Raynaud's, and stenosing tenosynovitis. Many clinicians utilize ultrasound (US) to guide these injections of the hand and wrist, typically utilizing an in-plane or out-ofplane technique to assist with anatomical needle positioning [4]. This procedure has been studied for trigger finger, De Quervain's tenosynovitis, carpal tunnel, and ganglion cyst aspiration. There is controversy in the literature regarding the increased accuracy of ultrasound-guided injections (USIs) as compared to landmarkbased-guided injections. One study showed that use of US increased the accuracy of carpometacarpal (CMC) joint injection from 63 to $94 \%$, but did not significantly improve injection accuracy of other hand joints [5]. This review will additionally outline the effects of compounds injected for each hand condition, such as corticosteroids, hyaluronic acid (HA), and botulinum neurotoxin. This article is based on previously conducted studies and does not contain any studies with human participants or animals performed by any of the authors.

\section{HAND OSTEOARTHRITIS}

Osteoarthritis is the most prevalent joint disorder in the elderly. The joints of the hand are the most affected joints in clinical $O A$ and significantly decrease an individual's ability to perform activities of daily living (ADLs). In the United States, the prevalence of symptomatic hand $\mathrm{OA}$ is $16 \%$ of the population [6]. The progression from the onset of disease to symptoms is not fully understood, however, one study of the US population estimated the risk of developing clinically significant hand $\mathrm{OA}$ in at least one hand by 85 years was $47 \%$ in women, $25 \%$ in men, $41 \%$ in whites, $29 \%$ in African Americans, and $47 \%$ in obese individuals [7]. From highest to lowest joint prevalence, hand $\mathrm{OA}$ affects the second distal interphalangeal joint (DIP), first CMC and third proximal interphalangeal joint (PIP), respectively [8].

Previously studied risk factors for the development of OA include age above 40, genetic predisposition, female gender, obesity, early menarche, articular hypermobility, increased grip strength, hand dominance, occupational manual work, and climate variation. Conversely, smoking has been found to be a protective factor [9].

Diagnosis of hand OA is largely clinical. The European League Against Rheumatism (EULAR) established guidelines for the diagnosis of hand OA in 2009. Most commonly, hand OA targets characteristic joints and manifests as pain with use as well as with mild inactivity stiffness. Individuals may also present with Heberden and Bouchard nodes. Symptomatic hand OA may present before imaging studies can confirm the diagnosis [10]. Management of hand OA is multidisciplinary and focuses primarily on pain management and improvement of functionality. The use of assisted devices, exercises to improve joint functionality, and orthoses are primary nonpharmacological interventions. Topical nonsteroidal anti-inflammatory drugs (NSAIDs) are the first-line pharmacologic treatment, followed by oral NSAIDs and chondroitin sulfate. If refractory to these treatments, intra-articular glucocorticoids may be considered, especially in the interphalangeal joints. Finally, surgical correction of structural abnormalities may be indicated [11].

\section{Intra-articular Therapies}

Intra-articular therapies, primarily for the CMC joints, are being assessed widely for the relief of 
pain and improvement of functionality in hand OA. Tested therapies include corticosteroids (CS), HA, and ketorolac.

Previously conducted systematic reviews of studies that compared outcomes in CS injections to placebo revealed that there was no significant difference between the two therapies at 20-26 weeks when the CMC joint was targeted [12]. In interphalangeal OA, however, CS injections improved pain with joint movement and joint swelling as compared to the placebo group [13].

The utility of HA injections is not well understood. One meta-analysis that compared intra-articular HA to placebo showed a significant improvement of pain with no improvement of functional capacity [13]. On the other hand, another meta-analysis of HA vs. placebo studies showed improvement of functional capacity without pain relief [12].

Systematic reviews that compared outcomes of HA injections to CS injections were varied but revealed similar results. It is important to note that both treatment groups led to improvement of pain [13]. Furthermore, HA had improved functionality via pinch force, while CS showed improved pain at 24 weeks [12]. When participants had moderate-to-severe hand $\mathrm{OA}$, however, functional improvement with HA injections was superior to CS. Additionally, pain reduction with HA was more gradual and long term, while CS was more acute [14]. In a systematic review of studies evaluating outcomes 6 months after injection, global hand pain, functionality, morning stiffness, and measures of perceived health were significantly improved in HA therapy [15]. One study that investigated combination $\mathrm{HA}$ and ketorolac intra-articular injections in the $\mathrm{CMC}$ joint revealed that the therapy improved pain at 1 month compared to HA alone [16].

\section{RHEUMATOID ARTHRITIS}

\section{Background Information}

Rheumatoid arthritis is a chronic autoimmune inflammatory polyarthritis with associated systemic symptoms. Inflammation of the joint synovium destroys the cartilage and bone [17]. Lack of treatment or response to it can have detrimental effects on ADLs. RA affects about $1 \%$ of the world's population and has a female preponderance. Numerous genetic and environmental factors have been identified in the development and severity of RA [18]. Analysis of the National Health and Nutrition Examination Survey (NHANES) database of the Centers for Disease Control (CDC) showed that older age, diabetes, obesity, smoking, and osteoporosis were strongly linked with RA [17]. Diagnosis of RA is typically made from the classification criteria published by the American College of Rheumatology and European League Against Rheumatism (ACE/EULAR). The criteria require involvement of at least one joint with diagnosis of synovitis, synovitis that cannot be better explained by any other disease, and a score of $\geq 6 / 10$ in four different domains: joint involvement, serology, acute-phase reactants, and duration of symptoms [19]. ACE/EULAR guidelines suggest early identification of RA and treatment initiation of disease-modifying antirheumatic drugs (DMARDs) and biologic therapies as optimal management. High-resolution US can greatly help with early identification, as it has high sensitivity for detection of synovitis and articular erosions and these are early manifestations of RA [20].

\section{Injection Technique}

While DMARDs and biologics remain the main treatments of RA, many patients still complain of refractory joint pain that often starts in the hands and feet. In terms of hand symptoms, RA commonly affects the PIP and metacarpophalangeal (MCP) joints. Corticosteroid injections are often used for this refractory pain and reduction of swelling but do not alter the disease course of RA [21]. Side effects observed with intra articular steroid injections are local skin pigment changes, subcutaneous fat wasting, tendon rupture, and systemic involvement, but are very rare [21]. A recent systematic review that examined the effectiveness of injected corticosteroid for treatment of pain in small and intermediate size joints showed that $10-20 \mathrm{mg}$ 
of methylprednisolone or triamcinolone injections are the most common steroids used for small joint pain [22]. A few studies in this review examined the MCP and IP joints and results showed that corticosteroid injections provided significant pain relief that lasted for several weeks up to several months; one study in particular for the IP joints showed that triamcinolone injections compared to methylprednisolone had greater improvements in patient-reported pain and functionality $[21,22]$. Recently, Wang et al. found that using $20 \mathrm{mg}$ of triamcinolone acetonide (TA), double the dose generally used for small joint RA, for the MCP and PIP joints combined with US for increased accuracy of injections, was very effective for treating refractory pain and swelling while having less side effects and having no implications on the original RA treatment plan that normally is comprised of DMARD's and biologics [23]. Currently, much of the literature on intraarticular corticosteroid injections focuses on medium and large joints like the wrist and knee; additional studies on small joints like the PIP and MCP joints should be done to further evaluate corticosteroid type, dose, and the utilization of US to optimize clinical and functional outcomes.

\section{CARPAL TUNNEL SYNDROME}

Carpal tunnel syndrome occurs when the median nerve becomes trapped beneath the flexor retinaculum ligament of the wrist, causing ischemia and loss of electrical conduction through the nerve. There are a variety of etiologies for CTS that are all likely due to mechanical compression or inflammation within the carpal tunnel. CTS affects about 3\% of the American adult population, but is three times more common in women [24]. In a study of California workers, incidence of CTS was 6.7 per 10,000 FTE (total hours worked in a year divided by $2000 \mathrm{~h}$ ) in 2007-2010 but decreased to 5.9 in 2011-2014 [25]. Repetitive motion of the wrist or use of electrical hand tools that vibrate can lead to increased pressure within the carpal tunnel. More specifically, repetitive cycles of $<10 \mathrm{~s}$ were ultimately more harmful than longer cycle times [26]. Other risk factors include a history of diabetes mellitus, obesity, hypothyroidism, pregnancy, and RA as well as a family history of CTS [24].

Diagnosis of CTS is largely clinical with presentation of pain and paresthesia in the distribution of the median nerve [24]. Severity is dependent on the cross-sectional area of median nerve that is affected. Mild disease involves $11.64 \mathrm{~mm}^{2}$, moderate disease affects $13.74 \mathrm{~mm}^{2}$, and severe CTS involves $16.8 \mathrm{~mm}^{2}$ [27]. Severity can additionally be determined clinically or via nerve conduction studies. Conservative treatment, such as wrist splints, physiotherapy, or steroid injections, is recommended in mild-to-moderate CTS due to fewer complications. Alternatively, surgical interventions are performed for severe CTS as they have been shown to improve symptoms, functionality, and nerve conduction [28].

\section{Intra-articular Injection Techniques}

Corticosteroid injections in the carpal tunnel are a mainstay of conservative treatment in CTS. This therapy is most useful for short-term pain relief. One study showed that $68 \%$ of participants required surgical treatment after an initial CS injection [29]. There is controversy regarding the safest location of these injections, but a comparative study of several locations found that injecting within the flexor carpi radialis tendon proximal to the carpal tunnel may be safest [30]. Using this in-plane ulnar approach has a significantly improved clinical response than injecting proximal to the wrist. The in-plane ulnar approach also significantly improved symptom severity compared to the proximal approach and the out-of-plane ulnar approach. None of the studied approaches were significantly different in functionality outcomes [31].

Another study revealed that $75 \%$ of CS injections were accurately placed solely using landmarks, while $8.7 \%$ penetrated and damaged the median nerve [32]. US guidance to locate the flexor carpi ulnaris tendon and median nerve can reduce this adverse effect [33]. A meta-analysis further revealed that the US 
technique significantly improved CTS severity after 12 weeks compared to landmark-guided CS injections. Functionality and electrical conduction did not reveal a significant difference between the two techniques [34].

\section{DE QUERVAIN'S TENOSYNOVITIS}

\section{Background Information}

Thickening and mucopolysaccharide accumulation of the sheath surrounding the tendons of the abductor pollicis longus (APL) and extensor pollicis brevis (EPB) causing pain and restricted motion of the wrist and thumb is known as De Quervain stenosing tenosynovitis (DQST) [35]. DQST is most prevalent in middle-aged and pregnant women [36]. Significant risk factors for this condition are the female gender, age greater than 40 years, and African-American race [35]. The prevailing hypothesis for the etiopathogenesis of DQST is that it is caused by repetitive and vigorous movements associated with certain occupations and activities. Despite this, a systematic review and meta-analysis on work-related causes of DQST showed no association between repetitive manual work and developing DQST [36]. Treatment for DQST usually starts with conservative measures like rest, non-steroidal anti-inflammatory drugs, and splinting [37].

\section{Injection Technique}

Corticosteroid injection of the first dorsal compartment tendon sheath is usually the next step after failure of conservative measures for DQST $[37,38]$. A meta-analysis investigating the effectiveness of corticosteroid injection for DQST showed that methylprednisolone, triamcinolonacetonide, and dexamethasone are the most common steroids used in these injections [37]. The studies in this meta-analysis compared the use of these injections to other interventions like placebo injections with sodium chloride, wrist thumb spica cast, and acupuncture. A few of the studies also combined steroid injections with other interventions such as the thumb spica cast and local anesthetics. The review results showed that patients whose intervention included steroid injections had statistically significant improvements in pain control, symptom resolution, and overall functional improvement compared to the patients that received other interventions without steroid injections like active and placebo controls [37]. Mardani-Kivi et al. observed that combining steroid injection and thumb spica casting was superior to injection alone in terms of functional outcomes [39]. These results confirm the supreme effectiveness of steroid injections in DQST. Additional randomized control trials should be performed to find a prototypical type of steroid, dosing strength, and combination interventions along with the injections.

The efficacy of corticosteroid injections is directly related to injection accuracy and anatomic variability of the first extensor compartment (FEC), which contains both the APL and EPB tendons [38]. A common variation is the creation of two sub-compartments secondary to a septum, which makes it much harder for the medication to reach the full surface of each sheath $[38,40]$. This problem can be targeted with the use of USIs and several studies have shown that USIs have increased efficacy compared to blind injections due to targeted medication delivery [40]. The three FEC variations found on US are complete, distal incomplete, and no sub-compartmentalization; performing US before injections can reveal the presence and amount of sub-compartmentalization and influence injection technique while adding no side effects [40]. Bing et al. recommend separate injections to both sub-compartments for complete sub-compartmentalization and proximal FEC injection for distal sub-compartmentalization [40]. Additional studies evaluating parameters such as pain control and functional improvement of USIs in DQST compared to blind injections should be conducted.

\section{GANGLION CYST}

\section{Background Information}

Ganglion cysts are benign soft tissue collections of fluid overlying joints or tendon sheaths 
found most commonly in the hand and wrist $[41,42]$. They are most prevalent in the age groups of $20 \mathrm{~s}-40$ s and have a slightly higher incidence in females [43]. The majority of ganglion cysts arise on the dorsal wrist followed by the volar wrist and flexor tendon sheaths in the hands [41]. The prevailing hypothesis for the pathogenesis of ganglions is that recurrent microtrauma to the joint capsule and ligaments triggers fibroblasts to synthesize HA and other mucopolysaccharides; these combine to create a thick, clear fluid that forms the ganglion [42]. Patients usually present with mild joint pain, weakness, or a palpable mass that may change in size over time $[42,43]$. Diagnosis is usually done by physical exam and it was classically thought US can confirm by showing a simple cystic lesion. However, Teefey et al. showed that many ganglion cysts in the dorsal or volar wrist are complex-appearing on US with features such as locules and walls, and this can have implications in the differential diagnosis of these cysts [43]. Many ganglion cysts can be treated with observation, as the pain associated with them is rarely debilitating and often resolves spontaneously. Some ganglia however may need intervention, like aspiration and surgical excision, due to increased pain or cosmetic purposes [42].

\section{Injection Technique}

Injections for ganglion cysts are used in conjunction with the aspiration technique; commonly injected substances are CS or hyaluronidase [42]. Recent studies have shown that there is no statistically significant difference in aspiration with and without corticosteroid injections in terms of improvement and recurrence of ganglion cysts. CS can additionally lead to side effects such as skin thinning and depigmentation [44]. Weinheimer et al. recently showed however that intra-articular corticosteroid injections may be useful in a certain type of ganglion cyst, a distal interphalangeal (DIP) cyst, which is associated with OA [45]. This study used a new technique by injecting $1 \mathrm{ml}$ of dexamethasone $4 \mathrm{mg} / \mathrm{ml}$ and $1 \%$ lidocaine in equal proportions into the volar flexion crease above the DIP joint; this method allows for increased precision of needle placement into the joint, reduction of side effects associated with steroids, and a success rate equivalent with the literature currently [45]. Overall, the use of steroid injections with aspiration should not be recommended for most types of ganglion cysts until further research with different injection techniques is performed and verified.

Hyaluronidase has also been used in conjunction with corticosteroid injection. Earlier studies showed significant improvements in resolution rates compared to corticosteroid alone but more recent studies have had variable results with high rates of recurrence with risk of allergic reaction [44]. Further studies using hyaluronidase and corticosteroid injections compared to aspiration alone should be conducted to measure long-term recurrence of ganglion cysts. Ultimately, a recent meta-analysis showed that surgical excision, while having higher complication rates, remains the best option to prevent recurrence of ganglion cysts, especially in comparison to aspiration with or without injections [42].

\section{RAYNAUD'S PHENOMENON}

Raynaud's phenomenon (RP) is an exaggerated thermoregulatory response triggered by cold temperature or emotional stress, resulting in local artery vasoconstriction secondary to sympathetic activation and local alpha receptors [46]. This ischemic disturbance in the fingers and toes manifests with characteristic color changes, significant pain or paresthesia, and complications such as disability and ulcers, which may require amputation $[47,48]$.

RP may be idiopathic, or primary, in nature. Secondary RP is often a result of smoking, occupational work involving vibrating tools, or inflammatory conditions such as systemic lupus erythematosus or systemic sclerosis [46, 49]. Primary RP is fairly common in the general population with a notably higher prevalence among women. This is likely due to estrogen which is involved in the translocation of a2Cadrenoreceptors to cell surfaces [46, 49]. Risk 
factors include family history among first-degree relatives, smoking, and female gender. Migraine has a positive association with RP, but the causal relationship remains unclear [49]. Diagnosis is largely clinical, but other methods are being explored including laser flow Doppler. Doppler allows detection of microcirculation changes, which may aid in early detection and establishing a more accurate prognosis [50]. Treatment includes trigger avoidance and medical management (i.e., calcium channel blockers, nitric oxide, etc.) [51]. In refractory cases, more invasive methods, such as botulinum neurotoxin-A (BTX-A) injections, may be indicated.

\section{Injection Techniques for Raynaud's Phenomenon}

Incorporation of BTX-A injections has yielded promising results. No precise mechanism of action has been identified. Most commonly cited areas of injection include neurovascular bundles at the MCP joint or more proximally at areas including the wrist, distal palm, para-ulnar artery, para-radial artery, and the common palmar digital artery [47, 48, 52]. Successful injection techniques include USI and use of conservative doses of BTX-A. Both of these methods aid in adverse transient intrinsic muscle weakness [52].

BTX-A injections have been largely efficacious. Outcomes include: decreased pain, increased oxygenation of the digits, decreased color abnormalities, improvement of chronic ulcers, relatively rapid symptom reduction, long-term therapeutic effects lasting multiple years and a reduction in the need for amputation [47, 48, 51-53]. Complications of the BTXA injection are currently limited to pain at the site of injection and temporary intrinsic hand weakness $[47,48]$.

Overall, BTX-A injections demonstrate a promising treatment option for those with refractory RP refractory [51]. BTX-A injections may reduce pain and complications of RP. Temporary intrinsic hand weakness or pain at the site of injection may occur $[47,48]$. Further studies incorporating larger sample sizes and long-term outcomes are needed to adequately define the benefit and harm of BTX-A injections in the setting of RP.

\section{GOUT}

Gout is the most common inflammatory arthritis. It is a condition in which hyperuricemia leads to monosodium urate crystal accumulation in intra- and extra-articular spaces. This results in severely painful, erythematous joints. Complications include gouty arthritis, tophi which may cause further sequelae such as kidney stones, long-term joint damage, and renal insufficiency. Decreased quality of life in gout leads to notable utilization of the health care system, primarily in the African-American community [54].

Hand involvement in gout is seen only after significant progression of the disease. Hand complications include subcutaneous tophi, bone and joint damage, tenosynovitis of the finger flexors, and nerve compression [55]. The incidence of gout has increased significantly in the US and Europe over the last few decades likely secondary to increased longevity and overall diet and lifestyle change among the general population [56-60]. Among men, gout is the most common inflammatory joint condition $[56,58]$. The prevalence of gout increases with age. At the time of diagnosis, women tend to have more comorbidities such as hypertension, congestive heart failure, and diabetes [56].

Modifiable risk factors for gout include obesity, metabolic syndrome, and hypertension. Additionally, diuretic use and consumption of animal purines, alcohol, and fructose are significant risk factors $[57,58,60]$. The diagnosis of gout is initiated clinically and confirmed with the visualization of needle-shaped, negatively birefringent urate crystals on joint aspiration [61]. Dual-energy computerized tomography (CT) is used for tracking the reduction of tophaceous joints. US is less sensitive than CT for gouty arthritis diagnosis, however may be used as first-line imaging in those who cannot receive CT [62].

Current treatment regimens are largely pharmacologic and preventative (i.e., avoiding 
meat, spirits, and sugary drinks). Acute gout flares are managed with non-steroidal anti-inflammatory drugs, colchicine, and CS. Allopurinol is the first-line agent for chronic gout, as it lowers urate levels. Febuxostat with a uricosuric and pegloticase are considered in the event that allopurinol is ineffective [63].

\section{Injection Techniques for Gout}

Per the criteria outlined by European League Against Rheumatism, glucocorticoids-either oral, intra-articular, or a combination-are recommended in the case of an acute gout flare [63]. However, intra-articular glucocorticoid injection efficacy in the setting of acute gout is largely unknown [64, 65].

Several smaller studies have examined glucocorticoid injection efficacy in the setting of acute gout. A study of 21 participants showed ultrasound-guided intra-articular glucocorticoid injections to the metatarsal phalangeal joint to be both safe and efficacious [66]. Another study saw rapid symptom relief, as early as $15 \mathrm{~min}$, at various joints in both the upper and lower extremities, with an intra-articular injection of triamcinolone coupled with mepivacaine. Relief lasted as long as several days. The dosage varied based on the joint involved. In addition to patient-reported symptom reduction, rheumatologists reported improvement as well [67].

Overall, intra-articular glucocorticoid injections are commonly regarded as appropriate therapy for acute gout. While studies with small sample sizes demonstrate promising results, efficacy remains to be established on a greater scale [64-66].

\section{STENOSING TENOSYNOVITIS}

Stenosing tenosynovitis, or trigger finger, is characterized by inflammation of the tendon and synovial sheath resulting in a functional narrowing manifesting as clicking, locking, and painful dysfunction of the involved digit. The etiology of trigger finger is unclear, however, repetitive movement is likely associated as demonstrated by the increased prevalence in those that use their hands strenuously [68].
The incidence of stenosing tenosynovitis is higher in women, diabetics, and those in their 50s and 60s [68]. Conditions such as Dupuytren's contracture also have a high association with stenosing tenosynovitis and vice versa [69]. The A1 pulley overlying the MCP joint is the most commonly involved location along the digit due to the high forces and pressure it endures. The fourth digit of the hand and thumb are the most commonly affected digits [68].

Diagnosis of stenosing tenosynovitis is predominantly clinical. A local lidocaine injection or imaging may be useful if diagnosis is elusive or if an underlying structural cause is present, respectively [68].

Management primarily involves reducing inflammation via splinting and steroid use or relieving narrowing with surgical intervention [68]. Best practice in comparison of open surgery, percutaneous surgery, and glucocorticoid injections remains unclear. Symptom reduction of stenosing tenosynovitis is similar between surgery and corticosteroid injections. While surgical intervention had lower recurrence of symptoms long term, it is associated with longer-lasting pain after the intervention [70]. Disability of arm shoulder and hand (DASH) score may be useful in determining which patients may benefit from surgery [71]. Surgery is often indicated in situations of refractory stenosing tenosynovitis, as it is largely understood that serial corticosteroid injections demonstrate diminishing returns [72-74].

\section{Injection Techniques}

Corticosteroid injections are typically done at the site of the A1 pulley. Various injection methods are used depending on the degree of space between the tendon and bone [73]. Corticosteroid injections are largely regarded as effective and are generally preferred to surgery given their less invasive nature. The long-term effectiveness is not as absolute as surgery; however, certain individuals have symptom reduction of stenosing tenosynovitis for as long as 10 years [70, 72, 74, 75]. Corticosteroid injections are most effective in women who are 
being treated for their first event of stenosing tenosynovitis [75]. Efficacy decreases in those with underlying inflammatory conditions or diabetics [73].

Single injection is considered to be the best method of care, as double injection does not further reduce symptoms $[70,71]$. In the event of full reduction of symptoms and then recurrence, a second injection may be used. There is less literature to confirm the efficacy of this and the literature that exists shows decreased rates of success [70, 71, 76]. DASH scores may be useful in determining the likelihood of failure following injection [71].

The use of USIs may increase reliability and reduce the likelihood of adverse events such as tendon rupture or digit necrosis, however results are varied and little to no benefit may be seen with the use of US in comparison to blind studies $[77,78]$.

\section{CONCLUSIONS}

Musculoskeletal hand conditions are contributing to increased rates of hand pain and disability. In most conditions, conservative management is recommended as the first-line treatment, but for moderate or more severe cases, in terms of increased pain or decreased functionality, corticosteroid injections are largely considered. In certain diseases, HA and botulinum neurotoxin have additionally been studied. These minimally invasive procedures have been shown in many cases to improve functionality, relieve pain, and reduce the need for further treatment in patients in the short term. More long-term treatment options like hand surgery are for the refractory pain cases. Further studies must be done to determine the most accurate and efficient injection techniques for each hand condition to improve patient outcomes.

\section{ACKNOWLEDGEMENTS}

Funding. No funding or sponsorship was received for this study or publication of this article.
Authorship. All named authors meet the International Committee of Medical Journal Editors (ICMJE) criteria for authorship for this article, take responsibility for the integrity of the work as a whole, and have given their approval for this version to be published.

Disclosures. Ivan Urits, Daniel Smoots, Lekha Anantuni, Prudhvi Bandi, Katie Bring, Amnon A. Berger, Hisham Kassem, Anh L. Ngo, Alaa Abd-Elsayed, Laxmaiah Manchikanti, Richard Urman, and Omar Viswanath have nothing to disclose. Alan Kaye is a member of the journal's Editorial Board.

Compliance with Ethics Guidelines. This article is based on previously conducted studies and does not contain any studies with human participants or animals performed by any of the authors.

Data Availability. Data sharing is not applicable to this article as no datasets were generated or analyzed during the current study.

Open Access. This article is licensed under a Creative Commons Attribution-NonCommercial 4.0 International License, which permits any non-commercial use, sharing, adaptation, distribution and reproduction in any medium or format, as long as you give appropriate credit to the original author(s) and the source, provide a link to the Creative Commons licence, and indicate if changes were made. The images or other third party material in this article are included in the article's Creative Commons licence, unless indicated otherwise in a credit line to the material. If material is not included in the article's Creative Commons licence and your intended use is not permitted by statutory regulation or exceeds the permitted use, you will need to obtain permission directly from the copyright holder. To view a copy of this licence, visit http:// creativecommons.org/licenses/by-nc/4.0/. 


\section{REFERENCES}

1. Dahaghin S, Bierma-Zeinstra SMA, Reijman M, Pols HAP, Hazes JMW, Koes BW. Prevalence and determinants of one month hand pain and hand related disability in the elderly (Rotterdam study). Ann Rheum Dis. 2005;64(1):99-104.

2. Green DJ, Jordan KP, Protheroe J, Van Der Windt DA. Development of hand phenotypes and changes in hand pain and problems over time in older people. Pain. 2016;157(3):569-76.

3. Bardin T, Voshaar MAHO, van de Laar MAFJ. The human and economic burden of difficult-to-treat gouty arthritis. Jt Bone Spine. 2015;82:eS2-8.

4. Chopra A, Rowbotham EL, Grainger AJ. Radiological intervention of the hand and wrist. Br J Radiol. 2016;89(1057):20150373.

5. To P, McClary KN, Sinclair MK, Stout BA, Foad M, Hiratzka S, Stern PJ. The accuracy of common hand injections with and without ultrasound: an anatomical study. Hand. 2017;12(6):591-6.

6. Marshall M, Watt FE, Vincent TL, Dziedzic K. Hand osteoarthritis: clinical phenotypes, molecular mechanisms and disease management. Nat Rev Rheumatol. 2018;14(11):641-56.

7. Qin J, Barbour KE, Murphy LB, Nelson AE, Schwartz TA, Helmick CG, Allen KD, Renner JB, Baker NA, Jordan JM. Lifetime risk of symptomatic hand osteoarthritis: the Johnston County Osteoarthritis Project. Arthritis Rheumatol. 2017;69(6):1204-12.

8. Wilder FV, Barrett JP, Farina EJ. Joint-specific prevalence of osteoarthritis of the hand. Osteoarthr Cartil. 2006;14(9):953-7.

9. Kalichman L, Hernández-Molina G. Hand osteoarthritis: an epidemiological perspective. Semin Arthritis Rheum. 2010;39(6):465-76.

10. Zhang W, Doherty M, Leeb BF, Alekseeva L, Arden NK, Bijlsma JW, Dincer F, Dziedzic K, Hauselmann HJ, Kaklamanis P, Kloppenburg M, Lohmander LS, Maheu E, Martin-Mola E, Pavelka K, Punzi L, Reiter S, Zimmermann-Gorska I. EULAR evidence-based recommendations for the diagnosis of hand osteoarthritis: report of a task force of ESCISIT. Ann Rheum Dis. 2009;68(1):8-17.

11. Kloppenburg M, Kroon FPB, Blanco FJ, Doherty M, Dziedzic KS, Greibrokk E, Haugen IK, HerreroBeaumont G, Jonsson H, Kjeken I, Maheu E, Ramonda R, Ritt MJPF, Smeets W, Smolen JS, Stamm TA, Szekanecz Z, Carmona L. 2018 update of the EULAR recommendations for the management of hand osteoarthritis. Ann Rheum Dis. 2019;78(1): $16-24$.

12. Trellu S, Dadoun S, Berenbaum F, Fautrel B, Gossec L. Intra-articular injections in thumb osteoarthritis: a systematic review and meta-analysis of randomized controlled trials. Jt Bone Spine. 2015;82(5): $315-9$.

13. Kroon FPB, Rubio R, Schoones JW, Kloppenburg M. Intra-articular therapies in the treatment of hand osteoarthritis: a systematic literature review. Drugs Aging. 2016;33(2):119-33.

14. Monfort J, Rotés-Sala D, Segalés N, Montañes FJ, Orellana C, Llorente-Onaindia J, Mojal S, Padró I, Benito P. Comparative efficacy of intra-articular hyaluronic acid and corticoid injections in osteoarthritis of the first carpometacarpal joint: results of a 6-month single-masked randomized study. Jt Bone Spine. 2015;82(2):116-21.

15. Tenti S, Pascarelli NA, Giannotti S, Galeazzi M, Giordano N, Fioravanti A. Can hybrid hyaluronic acid represent a valid approach to treat rizoarthrosis? A retrospective comparative study. BMC Musculoskelet Disord. 2017;18(1):1-9.

16. Koh SH, Lee SC, Lee WY, Kim J, Park Y. Ultrasoundguided intra-articular injection of hyaluronic acid and ketorolac for osteoarthritis of the carpometacarpal joint of the thumb: a retrospective comparative study. Medicine (Baltimore). 2019;98(19):e15506.

17. $\mathrm{Xu} \mathrm{B}$, Lin J. Characteristics and risk factors of rheumatoid arthritis in the United States: an NHANES analysis. PeerJ. 2017;2017(11):e4035.

18. Deane KD, Demoruelle MK, Kelmenson LB, Kuhn KA, Norris JM, Holers VM. Genetic and environmental risk factors for rheumatoid arthritis. Best Pract Res Clin Rheumatol. 2017;31(1):3-18.

19. Aletaha D, Neogi T, Silman AJ, Funovits J, Felson DT, Bingham CO, Birnbaum NS, Burmester GR, Bykerk VP, Cohen MD, Combe B, Costenbader KH, Dougados M, Emery P, Ferraccioli G, Hazes JMW, Hobbs K, Hawker G. 2010 Rheumatoid arthritis classification criteria: an American College of Rheumatology/European League Against Rheumatism collaborative initiative. Arthritis Rheumatol. 2010;62(9):2569-81.

20. Taljanovic MS, Melville DM, Gimber LH, et al. High-resolution US of rheumatologic diseases. Radiographics. 2015;35(7):2026-48.

21. Ferreira JF, Ahmed Mohamed AA, Emery P. Glucocorticoids and rheumatoid arthritis. Rheum Dis Clin N Am. 2016;42(1):33-46. 
22. Cushman DM, Ofek E, Syed RH, Clements N, Gardner JE, Sams JM, Mulvey JL, McCormick ZL. Comparison of varying corticosteroid type, dose, and volume for the treatment of pain in small- and intermediate-size joint injections: a narrative review. PM R. 2019;11:758-70.

23. Wang S, Wang X, Liu Y, Sun X, Tang Y. Ultrasoundguided intra-articular triamcinolone acetonide injection for treating refractory small joints arthritis of rheumatoid arthritis patients. Medicine (Baltimore). 2019;98(33):e16714.

24. Wipperman J, Goerl K. Carpal Tunnel syndrome: diagnosis and management. Am Fam Physician. 2016;94(12):993-9.

25. Jackson R, Beckman J, Frederick M, Musolin K, Harrison R. Rates of carpal tunnel syndrome in a state workers' compensation information system, by industry and occupation-California, 2007-2014. Morb Mortal Wkly Rep. 2018;67(39): 1094-7.

26. $\mathrm{Xu} \mathrm{B}$, Lin J. Characteristics and risk factors of rheumatoid arthritis in the United States: an NHANES analysis. Peer J. 2017;5:e4035.

27. Roomizadeh P, Eftekharsadat B, Abedini A, RanjbarKiyakalayeh S, Yousefi N, Ebadi S, Babaei-Ghazani A. Ultrasonographic assessment of carpal tunnel syndrome severity: a systematic review and metaanalysis. Am J Phys Med Rehabil. 2019;98:373-81.

28. Klokkari D, Mamais I. Effectiveness of surgical versus conservative treatment for carpal tunnel syndrome: a systematic review, meta-analysis and qualitative analysis. Hong Kong Physiother J. 2018;38(2):91-114.

29. Evers S, Bryan AJ, Sanders TL, Gunderson T, Gelfman R, Amadio PC. Corticosteroid injections for Carpal tunnel syndrome: long-term follow-up in a population-based cohort. Plast Reconstr Surg. 2017;140(2):338-47.

30. Racasan O, Dubert T. The safest location for steroid injection in the treatment of carpal tunnel syndrome. J Hand Surg Am. 2005;30(4):412-4.

31. Chen PC, Chuang CH, Tu YK, Bai CH, Chen CF, Liaw MY. A Bayesian network meta-analysis: comparing the clinical effectiveness of local corticosteroid injections using different treatment strategies for carpal tunnel syndrome. BMC Musculoskelet Disord. 2015;16(1):1-16.

32. Green DP, MacKay BJ, Seiler SJ, Fry MT. Accuracy of carpal tunnel injection: a prospective evaluation of 756 patients. Hand. 2020;15(1):54-8.
33. Lee JY, Park Y, Park KD, Lee JK, Lim OK. Effectiveness of ultrasound-guided carpal tunnel injection using in-plane ulnar approach: a prospective, randomized, single-blinded study. Medicine (United States). 2014;93(29):e350.

34. Babaei-Ghazani A, Roomizadeh P, Forogh B, Moeini-Taba SM, Abedini A, Kadkhodaie M, Jahanjoo F, Eftekharsadat B. Ultrasound-guided versus landmark-guided local corticosteroid injection for carpal tunnel syndrome: a systematic review and meta-analysis of randomized controlled trials. Arch Phys Med Rehabil. 2018;99(4):766-75.

35. Wolf JM, Sturdivant RX, Owens BD. Incidence of De Quervain's tenosynovitis in a young, active population. J Hand Surg Am. 2009;34(1):112-5.

36. Stahl S, Vida D, Meisner C, Lotter O, Rothenberger J, Schaller HE, Stahl AS. Systematic review and meta-analysis on the work-related cause of de quervain tenosynovitis: a critical appraisal of its recognition as an occupational disease. Plast Reconstr Surg. 2013;132(6):1479-91.

37. Rowland P, Phelan N, Gardiner S, Linton KN, Galvin $\mathrm{R}$. The effectiveness of corticosteroid injection for De Quervain's stenosing tenosynovitis (DQST): a systematic review and meta-analysis. Open Orthop J. 2015;9(1):437-44.

38. McDermott JD, Ilyas AM, Nazarian LN, Leinberry CF. Ultrasound-guided injections for De Quervain's tenosynovitis. Clin Orthop Relat Res. 2012;470(7): 1925-31.

39. Mardani-Kivi M, Karimi Mobarakeh M, Bahrami F, Hashemi-Motlagh K, Saheb-Ekhtiari K, Akhoondzadeh N. Corticosteroid injection with or without thumb spica cast for de quervain tenosynovitis. J Hand Surg Am. 2014;39(1):37-41.

40. Bing JH, Choi SJ, Jung SM, Ryu DS, Ahn JH, Kang $\mathrm{CH}$, Shin DR. Ultrasound-guided steroid injection for the treatment of de Quervain's disease: an anatomy-based approach. Skelet Radiol. 2018;47(11):1483-90.

41. Gude W, Morelli V. Ganglion cysts of the wrist: pathophysiology, clinical picture, and management. Curr Rev Musculoskelet Med. 2008;1(3-4): 205-11.

42. Head L, Gencarelli JR, Allen M, Boyd KU. Wrist ganglion treatment: systematic review and metaanalysis. J Hand Surg Am. 2015;40(3):546-553.e8.

43. Teefey SA, Dahiya N, Middleton WD, Gelberman $\mathrm{RH}$, Boyer MI. Ganglia of the hand and wrist: a sonographic analysis. Am J Roentgenol. 2008;191(3):716-20. 
44. Suen M, Fung B, Lung CP. Treatment of ganglion cysts. ISRN Orthop. 2013;2013(1):1-7.

45. Weinheimer K, Patrick N, Darowish M. Treatment of distal interphalangeal ganglion cysts by volar corticosteroid injection. Hand (New York). 2019;14(3):381-5.

46. Fardoun MM, Nassif J, Issa K, Baydoun E, Eid AH. Raynaud's phenomenon: a brief review of the underlying mechanisms. Front Pharmacol. 2016;7: $1-13$.

47. Segreto F, Marangi GF, Cerbone V, Persichetti P. The role of botulinum toxin a in the treatment of Raynaud phenomenon. Ann Plast Surg. 2016;77(3): 318-23.

48. Fregene A, Ditmars D, Siddiqui A. Botulinum toxin type A: a treatment option for digital ischemia in patients with Raynaud's phenomenon. J Hand Surg Am. 2009;34(3):446-52.

49. Garner R, Kumari R, Lanyon P, Doherty M, Zhang W. Prevalence, risk factors and associations of primary Raynaud's phenomenon: systematic review and meta-analysis of observational studies. BMJ Open. 2015;5(3):1-9.

50. Mosdósi B, Bölcskei K, Helyes Z. Impairment of microcirculation and vascular responsiveness in adolescents with primary Raynaud phenomenon. Pediatr Rheumatol. 2018;16(1):1-8.

51. Neumeister MW, Webb KNB, Romanelli M. Minimally invasive treatment of raynaud phenomenon: the role of botulinum type A. Hand Clin. 2014;30: $17-24$.

52. Zhang X, Hu Y, Nie Z, Song Y, Pan Y, Liu Y, Jin L. Treatment of Raynaud's phenomenon with botulinum toxin type A. Neurol Sci. 2015;36(7):1225-31.

53. Smith L, Polsky D, Franks AG. Botulinum toxin-A for the treatment of Raynaud syndrome. Arch Dermatol. 2012;148(4):426-8.

54. Singh JA, Bharat A, Khanna D, Aquino-Beaton C, Persselin JE, Duffy E, Elashoff D, Khanna PP. Health care utilization in patients with gout: a prospective multicenter cohort study. BMC Musculoskelet Disord. $2017 ; 18(1): 233$.

55. Meyer $\mathrm{Zu}$ Reckendorf G, Dahmam A. Hand involvement in gout. Hand Surg. Rehabil. 2018. https://doi.org/10.1016/j.hansur.2018.02.005.

56. Drivelegka P, Sigurdardottir V, Svärd A, Jacobsson LTH, Dehlin M. Comorbidity in gout at the time of first diagnosis: sex differences that may have implications for dosing of urate lowering therapy. Arthritis Res Ther. 2018;20(1):108.
57. Evans PL, Prior JA, Belcher J, Mallen CD, Hay CA, Roddy E. Obesity, hypertension and diuretic use as risk factors for incident gout: a systematic review and meta-analysis of cohort studies. Arthritis Res Ther. 2018;20(1):136.

58. Roddy E, Choi HK. Epidemiology of gout. Rheum. Dis. Clin. 2014;40:155-75.

59. Zhu Y, Pandya BJ, Choi HK. Prevalence of gout and hyperuricemia in the US general population: the National Health and Nutrition Examination Survey 2007-2008. Arthritis Rheum. 2011;63(10):3136-41.

60. Saag KG, Choi H. Epidemiology, risk factors, and lifestyle modifications for gout. Arthritis Res Ther. 2006;8:S2-10.

61. Reuss-Borst M, Tausche A-K. Update on gout and calcium pyrophosphate deposition (CPPD). Dtsch Med Wochenschr. 2018;143(16):1157-66.

62. Klauser AS, Halpern EJ, Strobl S, Abd Ellah MMH, Gruber J, Bellmann-Weiler R, Auer T, Feuchtner G, Jaschke W. Gout of hand and wrist: the value of US as compared with DECT. Eur Radiol. 2018;28(10): 4174-81.

63. Richette P, Doherty M, Pascual E, Barskova V, Becce F, Castañeda-Sanabria J, Coyfish M, Guillo S, Jansen TL, Janssens H, Lioté F, Mallen C, Nuki G, PerezRuiz F, Pimentao J, Punzi L, Pywell T, Bardin T. 2016 updated EULAR evidence-based recommendations for the management of gout. Ann Rheum Dis. 2017;76:29-42.

64. Wechalekar MD, Vinik O, Moi JHY, Sivera F, Van Echteld IAAM, Van Durme C, Falzon L, Bombardier C, Carmona L, Aletaha D, Landewé RB, Van Der Heijde DMFM, Buchbinder R. The efficacy and safety of treatments for acute gout: results from a series of systematic literature reviews including Cochrane reviews on intraarticular glucocorticoids, colchicine, nonsteroidal antiinflammatory drugs, and interleukin-1 inhibitors. J Rheumatol. 2014;41(Suppl. 92):15-25.

65. Wechalekar MD, Vinik O, Schlesinger N, Buchbinder R. Intra-articular glucocorticoids for acute gout. Cochrane Database Syst Rev. 2013;4: CD009920.

66. Kang MH, Moon KW, Jeon YH, Cho SW. Sonography of the first metatarsophalangeal joint and sonographically guided intraarticular injection of corticosteroid in acute gout attack. J Clin Ultrasound. 2015;43(3):179-86.

67. Andrés M, Begazo A, Sivera F, Vela P, Pascual E. AB0815 intraarticular triamcinolone plus mepivacaine provides a rapid and sustained relief for acute 
gouty arthritis. Ann Rheum Dis. 2016;75(Suppl 2): 1182.2.

68. Makkouk AH, Oetgen ME, Swigart CR, Dodds SD. Trigger finger: etiology, evaluation, and treatment. Curr Rev Musculoskelet Med. 2008;1(2):92-6.

69. Yang K, Gehring M, Bou Zein Eddine S, Hettinger P. Association between stenosing tenosynovitis and Dupuytren's contracture in the hand. Plast Reconstr Surg Glob Open. 2019;7(1):e2088.

70. Fiorini HJ, Tamaoki MJ, Lenza M, Gomes dos Santos JB, Faloppa F, Belloti JC. Surgery for trigger finger. Cochrane Database Syst Rev. 2018;2(2):CD009860.

71. Sheikh E, Peters JD, Sayde W, Maltenfort M, Leinberry C. A prospective randomized trial comparing the effectiveness of one versus two (staged) corticosteroid injections for the treatment of stenosing tenosynovitis. Hand (New York). 2014;9(3):340-5.

72. Kerrigan CL, Stanwix MG. Using evidence to minimize the cost of trigger finger care. J Hand Surg Am. 2009;34(6):997-1005.

73. Akhtar S, Burke FD. Study to outline the efficacy and illustrate techniques for steroid injection for trigger finger and thumb. Postgrad Med J. 2006;82(973):763-6.

74. Benson LS, Ptaszek AJ. Injection versus surgery in the treatment of trigger finger. J Hand Surg Am. 1997;22(1):138-44.

75. Wojahn RD, Foeger NC, Gelberman RH, Calfee RP. Long-term outcomes following a single corticosteroid injection for trigger finger. J Bone Jt Surg Am. 2014;96(22):1849-54.

76. Dardas AZ, VandenBerg J, Shen T, Gelberman RH, Calfee RP. Long-term effectiveness of repeat corticosteroid injections for trigger finger. J Hand Surg Am. 2017;42(4):227-35.

77. Yildizgören MT, Velioglu O, Guler H. Trigger finger: ultrasound-guided injection with an in-plane approach under the A1 pulley. Ther Adv Musculoskelet Dis. 2016;8:51-2.

78. Cecen GS, Gulabi D, Saglam F, Tanju NU, Bekler HI. Corticosteroid injection for trigger finger: blinded or ultrasound-guided injection? Arch Orthop Trauma Surg. 2015;135(1):125-31. 